\title{
Assessment of the Artificial Habitat in Shrimp Aquaculture Using Environmental Pattern Classification
}

\author{
José Juan Carbajal Hernández, \\ Luis Pastor Sánchez Fernández, and Marco Antonio Moreno Ibarra \\ Centre of Computer Research - National Polytechnic Institute, Av. Juan de Dios Bátiz, Col. \\ Nva. Industrial Vallejo, México D.F., México. 57296000, Ext. 56573 \\ juancarvajalesagitario.cic.ipn.mx, \\ \{lsanchez, marcomoreno\} @cic.ipn.mx
}

\begin{abstract}
This paper presents a novel model for assessing the water quality for the artificial habitat in shrimp aquaculture. The physical-chemical variables involved in the artificial habitat are measured and studied for modeling the environment of the ecosystem. A new physical-chemical index $(\Gamma)$ classifies the behavior of the environmental variables, calculating the frequency and the deviations of the measurements based on impact levels. A fuzzy inference system (FIS) is used for establishing a relationship between environmental variables, describing the negative ecological impact of the concentrations reported. The FIS uses a reasoning process for classifying the environmental levels providing a new index, which describes the general status of the water quality (WQI); excellent, good, regular and poor.
\end{abstract}

Keywords: Artificial intelligence, fuzzy inference systems, classification, water management.

\section{Introduction}

Water management is an important factor in shrimp aquaculture, where the ecosystem must be under control. A disestablished habitat is not conducive for a good farming, also an organism with a weakened immunological system is more likely for getting sick (for example Taura virus, Mancha Blanca, Cabeza Amarilla, Etc.) The main purpose on water management and aquaculture systems is to control and maintain the optimal conditions for the surviving and good growing of the organisms to the closest to a natural ecosystem [1]. The assessment of the water quality can be estimated using the relationships between the physical, chemical and biological parameters. The combination of the environmental variables determines the status of the water quality [2], [3]. Actually, in the world the laws do not provide enough criteria to resolve this problem and the ecological standards only describe the toxicity limits of the pollutants into the water bodies and the methodologies to measure them [4], [5], [6], [7].

Environmental variables have some concentration limits, where low or high concentrations (depending of the variable) can be harmful for the organism [1], [2], [3]. Following this behaviors, it is possible to implement a model in the attention that those limits and changes in the variables can be used for determining when a 
concentration is good or bad for shrimp, and how the combination of these variables affects the water quality in the artificial shrimp habitat. This strategy will decrease the negative situations; consequently also it will decrease the stress in the organism, and low mortality rates.

A new model for assessing the water quality in artificial shrimp habitats is presented. The system includes a statistical model for evaluating physical-chemical concentrations and a fuzzy inference system for classifying the status of the ecosystem. Litopenaeus vanammei shrimp, whose is cultivated in farms located in Sonora, Mexico, has been studied in this work; therefore toxic concentrations for this organism will be analyzed for the construction of the FIS.

\section{Materials and Methods}

\subsection{Classification Levels}

In order to classify the behavior of a physical-chemical variable it is needed to define the limits of optimal or harmful concentrations [8]. The classification levels of the physical-chemical variables (status) are defined in Table 1; for dissolved oxygen we chosen "hypoxia", "low" and "normal", for the temperature and salinity variables we chosen "low", "normal" and "high", and for the pH variable we chosen "acid", "low", "normal", "high", and "alkaline. Tolerance (Tol) and limits (Lim) are used to determine the bounds of ranges, where values can be considered closer or further than a specified level.

Table 1. Classification levels, tolerances and limits of physical-chemical variables

\begin{tabular}{lccccccc}
\hline Variables & $\begin{array}{c}\text { Hypoxia } \\
\text { Acid }\end{array}$ & Low & Normal & High & Alkaline & Tol & Lim \\
\hline Temp $\left({ }^{\circ} \mathrm{C}\right)$ & ------ & $0-23$ & $23-30$ & $30-\infty$ & ------ & \pm 1 & $\mp 1$ \\
Sal $(\mathrm{mg} / \mathrm{L})$ & ------- & $0-15$ & $15-25$ & $25-\infty$ & ------- & \pm 1 & $\mp 1$ \\
DO $(\mathrm{mg} / \mathrm{L})$ & $0-3$ & $3-6$ & $6-10$ & $10-\infty$ & ------ & \pm 0.5 & $\mp 0.5$ \\
PH & $0-4$ & $4-7$ & $7-9$ & $9-10$ & $10-14$ & \pm 0.5 & $\mp 0.5$ \\
\hline
\end{tabular}

\subsection{Preprocesing}

The environmental signals have several peaks values, this behavior can be generated due a failed device, human error or noise; in order to minimize those effects the physical-chemical signals are smoothed for an accurate assessment (Fig 1). A moving average weighted filter works using an average of signal points (measured concentrations) for producing new output points of the new filtered signal and smoothing it [9], [10]. The smoothing process of the physical-chemical variables can be calculated as follows:

$$
y(n)=\sum_{i=0}^{N} b_{i} x(n-i)
$$


where $x(n)$ is the original signal, $y(n)$ is the new output signal, $N$ is known as the filter order, $b_{i}$ are the Henderson 7 terms coefficients defined as $H=[-0.05874,0.05874$, $0.29371,0.41259,0.29371,0.05874,-0.05874]$. The smoothing process using a moving average weighted filter is:

$$
y(n)=[-0.05874 x(n)+0.05874 x(n-1)+\cdots-0.05874 x(n-7)]
$$
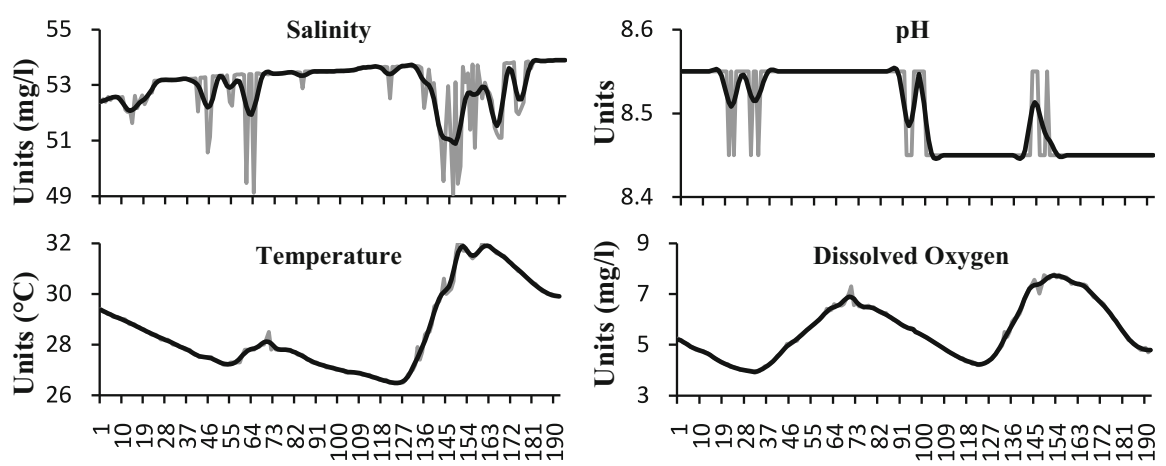

Measurements

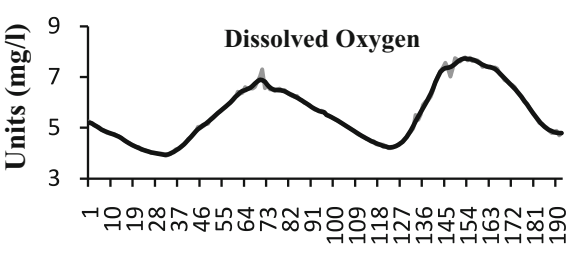

Measurements

Fig. 1. Original and smoothed signals of the physical-chemical variables using a moving average

\section{Physical - Chemical Assessment Index ( $\Gamma)$}

The Physical - chemical assessment index $(\Gamma)$ classifies the level that a physical chemical variable reports based on the Table 1 . The $\Gamma$ index comprises three factors and is well documented.

\section{Index 1: $\alpha$ (Frequency)}

The frequency represents the percentage of individual tests that do not meet the objectives (failed tests).

$$
\alpha=\frac{m_{f}}{m_{T}}
$$

where $\alpha$ is the failed index, $m_{f}$ is the number of failed tests and $m_{T}$ is the number of total tests of the variable.

\section{Index 2: $\beta$ (Amplitude)}

The average by which the failed test values do not meet their objectives, is calculated in three steps. The number of times by which an individual concentration is greater than (or less) the objective is termed a "deviation" and is expressed as follows. When the value must not exceed the level:

$$
e=\frac{m-l_{a}}{t_{a}-l_{a}}
$$

where $e$ is the deviation of the failed test; $m$ is the value of the test; la is the upper limit of the range to evaluate; $t a$ is the upper tolerance. When the value must not fall below the level: 


$$
e=\frac{l_{b}-t_{b}}{l_{b}-m}
$$

where $l b$ is the lower limit of the range evaluated; $t b$ is the lower tolerance of the range (i. e. if normal salinity has a range [15-23 $\mathrm{mg} / \mathrm{l}]$, tolerance is 1 and limit is -1 , therefore $l a$ is $22 \mathrm{mg} / \mathrm{l}$ and $t a$ is $24 \mathrm{mg} / \mathrm{l}$ and $t b$ is 14 and $l b$ is 16). The average of the deviation is calculated as an index $(\beta)$ :

$$
\beta=\frac{\sum_{i}^{n} e_{i}}{m_{T}}
$$

where $i: 1,2, \ldots \mathrm{n} ; n$ is the number of calculated deviations; $m_{T}$ is of total tests.

\section{Index 3: $\Gamma$ (Physical - chemical assessment index)}

The Physical - chemical assessment index $(\Gamma)$ classifies the behavior of the variable establishing a level status (Table 1). The $\Gamma$ index can be expressed as follows:

$$
\Gamma=\sqrt{\frac{\alpha^{2}+\beta^{2}}{2}} .
$$

The $\Gamma$ result can be interpreted as follows:

- If $0 \leq \Gamma<1$, the variable behavior is classified inside the evaluated range.

- If $\Gamma \geq 1$, the variable behavior is classified totally outside the evaluated range.

\subsection{Fuzzy Inference System}

The Fuzzy inference systems (FIS) theory was applied in this study providing a nonlinear relationship between input sets (Physical-chemical variables) and output set (Water Quality Index) [11], [12]. The $\Gamma$ index can be used for calculating the membership functions of the fuzzy inference system, the expression of the fuzzy input can be expressed as follows:

$$
\mu_{v}=\left\{\begin{array}{lr}
0 & 1<\Gamma \\
1-\Gamma & 0 \leq \Gamma \leq 1
\end{array}\right.
$$

where $v$ is the desired variable.

The input set of the FIS can be expressed as follows:

$$
z^{l}=\left[\mu_{t e m p}^{i}, \mu_{s a l}^{j}, \mu_{D O}^{k}, \mu_{p H}^{l}\right]
$$

where $i, j, k$ and $l$ are the range of the evaluated variables (high, normal, low, alkaline, acid, and hypoxia respectively).

\subsection{Reasoning Process}

There are some expressions that are frequently used by experts in water quality; those expressions will be helpful for the construction of the FIS [11], [12]. These types of 
expressions built the fuzzy language and they are represented as a rule set, and they can be expressed as follows:

Rule 1: If Temp is normal and Salt is normal and $\mathbf{p H}$ is normal and DO is normal then WQI is Excellent

Rule 2: If Temp is normal and Salt is normal and $\mathbf{p H}$ is normal and DO is low then WQI is Good

The output rules functions are fuzzy expressions that can be determined as follows:

$$
\mu_{R}=\min \left\{\mu_{t e m p}^{i}, \mu_{s a l}^{j}, \mu_{D O}^{k}, \mu_{p H}^{l}\right\} .
$$

Fig. 3 illustrates the operation of rules 1 and 2 .

The size of the set rule depends of the number of rules that are involved in the environment; a total of 135 rules have been used in this case.

\subsection{Water Quality Status}

The ecosystem is always changing, and the combination of the variable concentrations defines the status of the water quality. If a high impact variable reports harmful concentrations, therefore the status of the water quality will be deteriorated [1], [2], [3], [12]. Water quality status has been classified in four levels, whose involve all the hypothetical situations in a shrimp pond:

1. Excellent: physical-chemical variables report concentrations in the optimal range.

2. Good: one variable reports concentrations out of the optimal range; however this situation do not represents danger in the shrimp.

3. Regular: some variables report concentrations out of the optimal range, and the combination between them represents certain stress level in the organism.

4. Poor: all the variables concentrations are out of the optimal ranges, or a variable with a high impact level presents concentrations that could generate a potentially danger situation in the pond (i. e. extremely low oxygen concentrations).

The membership rules must be processed by an output membership function in order to determine the fuzzy outputs. The output membership function proposed for water quality is showed in Fig. 2. Trapezoidal membership functions were used to represent poor, regular, good, and excellent fuzzy sets [11]. They are represented as:

$$
\mu_{W Q I}(x, a, b, c, d)=\min \left\{\frac{x-a}{b-a}, 1, \frac{d-x}{d-c}\right\}
$$

where $a, b, c$ and $d$ are the membership parameters. 


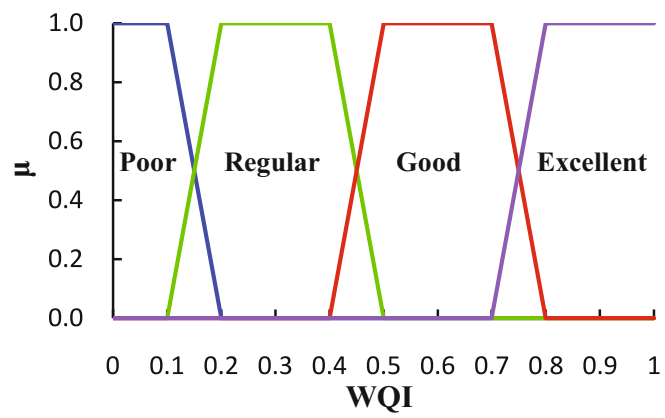

Fig. 2. Membership functions for WQI

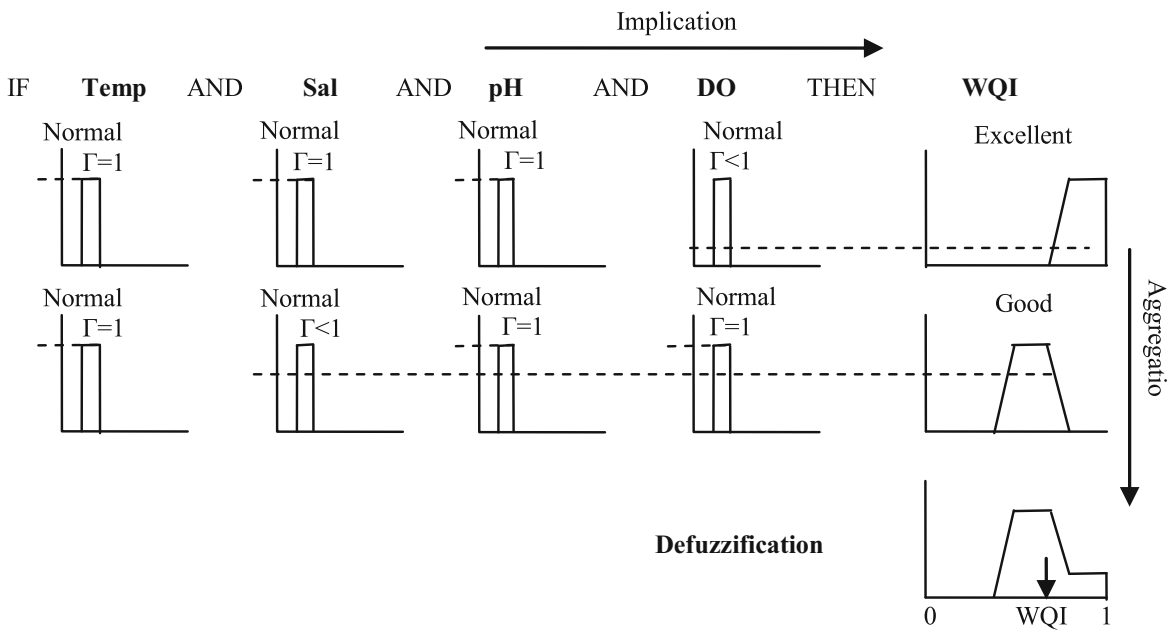

Fig. 3. Inference process where the membership functions of rules are used to determine the final membership function

The values of WQI memberships functions $\left(\mu_{W Q I}\right)$ are determined by matching with the rule memberships (Fig. 3).

\subsection{Aggregation}

The aggregation process generates one final function $\left(\mu_{\text {out }}\right)$ using all the output membership functions $\left(\mu_{R}\right)$. The WQI index is calculated using the gravity center of the function [7]:

$$
W Q I=\frac{\int x \mu_{\text {out }}(x) d x}{\int \mu_{\text {out }}(x) d x} .
$$

The final score for the WQI index has a $[0.078,0.87]$ range, in order to have a $[0,1]$ range, the output is normalized using the next equation: 


$$
x_{n}=\frac{x-\min (x)}{\max (x)-\min (x)}
$$

where $x$ is the output of the fuzzy system, $x_{n}$ is the new normalized result.

\section{Experimental Results}

In order to estimate how the WQI index performs with real data, data sets of environmental measurements obtained from farms on Rancho Chapo, located in Sonora, Mexico were used as fundamental patterns.

The measurements of the variables depend of the exactitude of how a supervisor monitors the aquaculture system. Temperature, dissolved oxygen, salinity and $\mathrm{pH}$ were measured using a sensor for each variable. The monitoring frequency was of 4 measurements per hour. The data set contains four months of measurements with 96 values by day; a register of 9312 values per variable has been measured.
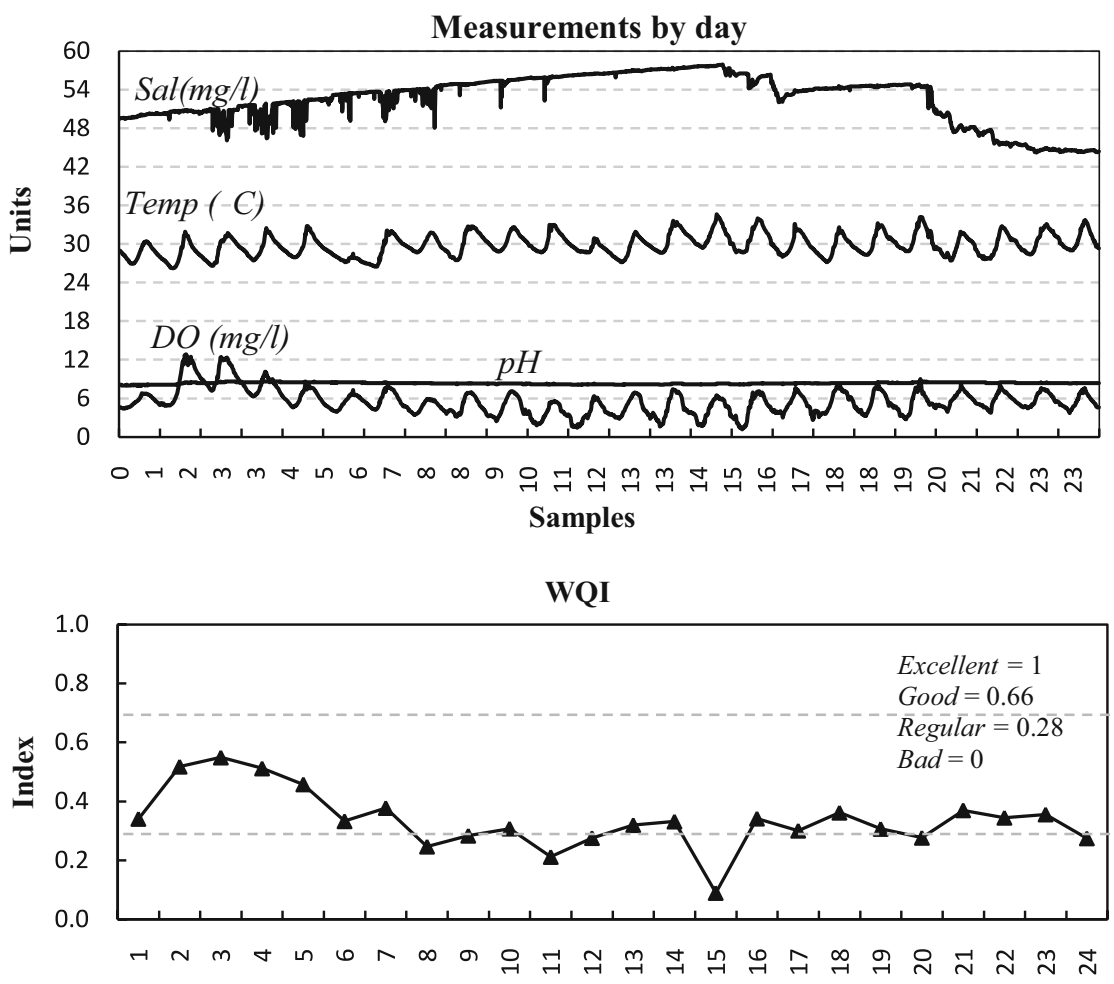

Results by day

Fig. 4. a) Measurements of the environmental variables in one month of farming; b) Results of the evaluation of the habitat in the farm using the WQI 
The experimental phase was carried out as follows: one month of measurements was extracted from data base (Fig 3a), the $\Gamma$ index is calculated using one day of information (96 measurements), and this process is repeated using the rest of the month. The $z$ vector is built using the $\Gamma$ classifications and it is processed in the fuzzy inference system. The final result is normalized in order to establish a $[0,1]$ index.

The WQI results are shown in Fig. 4b. In Fig. 4a the salinity is always in a high level, the temperature is increasing and the dissolved oxygen has an oscillatory behavior where it changes between normal and low concentrations; those behaviors affect directly the habitat of the environment reporting regular and bad water quality (i.e. in Fig. $4 \mathrm{~b}$, the $15^{\text {th }}$ day DO reported most of the concentrations in low and hypoxia level, which generates a por state).

\section{Conclusion}

In this paper a new algorithm which is based on fuzzy inference systems has been introduced. The model to assess the water quality status was built in two phases; the first classifies the levels of the physical - chemical variables; the second evaluates the negative ecological impacts in order to analyze the water quality status in the shrimp habitat. Experimental results have shown that this algorithm is an efficient way to improve water management in shrimp aquaculture.

Acknowledgments. The authors of the present paper would like to thank the following institutions for their support to develop this work: National Polytechnic Institute, Mexico, Biology Research Center of Sonora (CIB) and CONACyT.

\section{References}

1. Casillas, R., Magallón, F., Portillo, G., Osuna, P.: Nutrient mass balances in semi-intensive shrimp ponds from Sonora, Mexico using two feeding strategies: Trays and mechanical dispersal. In: Aquaculture, vol. 258, pp. 289-298. Elsevier, Amsterdam (2006)

2. Martínez, R.: Cultivo de Camarones Pendidos, Principios y Practica. AGT Editor S.A. (Ed.) (1994)

3. Páez, O. F.: Camaronicultura y Medio Ambiente. Instituto de Ciencias del mar y Limnología, UNAM, México, pp. 271-298 (2001)

4. (INE) Instituto Nacional de Ecología: La calidad del agua en los ecosistemas costeros de México (2000)

5. (SEMARNAP), Secretaría de Medio Ambiente, Recursos Naturales y Pesca.: NOM-001ECOL-1996

6. (CCME) Canadian Council of Ministers of the Environment (Canada), An assessment of the application and testing of the water quality index of the Canadian Council of Ministers of the Environment for selected water bodies in Atlantic Canada. National indicators and reporting office, http: / / www.ec.gc. ca/soer-ree/N (accessed August 2007)

7. (NSF) National Sanitation Foundation International (2005), http: / / www.nsf.org (accessed August 2007)

8. Yew-Hu, C.: Water quality requirements and management for marine shrimp culture. In: Proceedings of the Special Session on Shrimp Farming World Aquaculture Society, Baton Rouge, LA USA, pp. 144-156 (1992) 
9. Emmanuel, C.: Digital signal processing: a practical approach. Addison-Wesley, Reading (1993)

10. Proakis, J., Manolakis, D.: Tratamiento digital de señales. Pearson Education, Vol. 1(4), Ed. España (2007)

11. Ocampo, W., Ferré, N., Domingo, J., Schuhmacher, M.: Assessing water quality in rivers with fuzzy inference systems: A case study. In: Environment International, vol. 32, pp. 733-742. Elsevier, Amsterdam (2006)

12. Chow, M.-Y.: Methodologies of using neural network and fuzzy logic technologies for motor incipient fault detection. World Scientific, Singapore (1997) 